\title{
UM ESTUDO SOBRE A DEPRESSÃO E O SUICIDIO EM ADOLESCENTES
}

\author{
Márcia Gomes Inácio Vital ${ }^{1}$
}

RESUMO: O objetivo deste artigo é trazer algumas reflexões sobre a depressão e o suicídio em adolescentes, pois a adolescência consiste em uma etapa do desenvolvimento humano marcada por inúmeras transformações, e é um momento em que podem manifestar diversos transtornos, tornando-se importante a sua adequada identificação. Apresentar quais os sinais da depressão e do suicídio. Identificar fatores de riscos que levam a depressão e ao suicídio e compreender como a família pode estar sendo fundamental nesse processo. Para essa proposito, o estudo é de natureza básica, forma de abordagem qualitativa e a pesquisa é explicativa de cunho bibliográfico. Para fundamentar este trabalho utilizamos alguns autores como Aberastury e Knobel (1981), Baptista e Oliveira (2004), Benicasa e Rezende (2006), Braga e Dell' anglio (2013), Eisenstein (2005), Esteves e Gavões (2006), Mota e Rocha (2012).

Palavras- chave: Adolescente. Depressão. Família. Suicídio.

ABSTRACT: The purpose of this article is to bring some reflections on depression and suicide in adolescents, as adolescence is a stage of human development marked by innumerable transformations, and it is a time when they can manifest various disorders, making it important to its proper identification. Present the signs of depression and suicide. Identify risk factors that lead to depression and suicide and understand how the family may be fundamental in this process. For this purpose, the study is of a basic nature, a form of qualitative approach and the research is explanatory of bibliographic nature. To support this work, we used some authors such as Aberastury and Knobel (198I), Baptista and Oliveira (2004), Benicasa and Rezende (2006), Braga and Dell' anglio (2013), Eisenstein (2005), Esteves and Gavões (2006), Mota and Rocha (2012).

Keywords: Adolescent. Depression. Family. Suicide.

\footnotetext{
${ }^{1}$ Formação acadêmica: Pós-Graduada em Psicopedagogia Institucional, Clínica e Educaçao Infantil: Faculdade Futura, mantida pelo instituto de Ciência, Educação e Tecnologia de Votuporanga. Email: marciagomevital@gmail.com.
} 


\section{INTRODUÇÃO}

Este artigo propôs trabalhar a depressão e o suicídio em adolescente, pois na atualidade há um grande aumento de adolescente apresentando depressão, e acometendo suicídio.

Para um melhor entendimento do assunto, percorreremos um caminho de inicialmente entender sobre, quando começa a adolescência, o que é adolescente, suas mudanças biológicas, físicas e psicológicas. Em seguida, veremos o que é depressão e suicídio, seus sinais e sintomas. E por último quais os fatores de riscos e as prevenções que podem ser tomadas, e esclarecer a importância do papel dos pais no processo de formação do sujeito e nos cuidados e atenção nessa fase de vida.

A depressão vem crescendo cada vez mais no mundo. Pois é um transtorno que afeta o desenvolvimento e crescimento do adolescente, no que impede de ter uma vida social, alienando e ficando isolado da família e do mundo e pode até cometer o suicídio.

O estudo é de natureza básica, forma de abordagem qualitativa e a pesquisa é explicativa e como recursos para elaboração foram utilizadas bibliografias como livros e artigos científicos, de alguns autores como: Aberastury e Knobel (1981), Baptista e Oliveira (2004), Benicasa e Rezende (2006), Braga e Dell' anglio (2013), Eisenstein (2005), Esteves e Gavões (2006), Mota e Rocha (2012) entre outros.

\section{ADOLESCÊNCIA}

Adolescência é o período de transição entre a infância e a vida adulta, caracterizado pelos impulsos do desenvolvimento físico, mental, emocional, sexual e social e pelos esforços do indivíduo em alcançar os objetivos relacionados às expectativas culturais da sociedade em que vive. EISENSTEIN (2005, p.6).

Ele continua dizendo que, a adolescência se inicia com as mudanças corporais da puberdade e termina quando o indivíduo consolida seu crescimento e sua personalidade, obtendo progressivamente sua independência econômica, além da integração em seu grupo social. EISENSTEIN (2005, p. 7).

Schilichting, Moraes (2018) dizem que a adolescência é uma etapa na qual ocorrem acentuadas transformações físicas. A busca por identidade faz do adolescente um ser crítico, inquieto e, muitas vezes insatisfeito já que, enfrenta um novo corpo, tem novas percepções familiares e sociais. (p. 359)

Para Martins, Trindade e Almeida (2003) A adolescência deve ser entendida como um período e um processo psicossociológico de transição entre a infância e a fase adulta e que depende das circunstâncias sociais e históricas para a formação do sujeito. Sendo assim, a adolescência é um período/processo em que o adolescente é convidado a participar, dinamicamente, da construção de um projeto seu, o seu projeto de vida. Neste processo, a identidade, a sexualidade, o grupo de amigos, os valores, a experiência 
e a experimentação de novos papéis tornam-se importantes nas relações do adolescente com o seu mundo. Nessa fase, o adolescente procura se definir por meio de suas atividades, de suas inclinações, de suas aspirações e de suas relações afetivas (p.556).

Segundo Aberastury e Knobel (198I) a adolescência não deve ser vista apenas como uma passagem para a vida adulta. A criança entra na adolescência com muitos conflitos e incertezas e ela precisa sair dela com sua maturidade estabilizada, com caráter e personalidades adultos. "A consequência final da adolescência seria um conhecimento de si mesmo como entidade biológica no mundo, o todo biopsicossocial de cada ser nesse momento de vida" (ABERASTURY E KNOBEL, i98i, p. 30).

Ao longo do século, a adolescência passou a ser reconhecida como um momento crítico da vida, temida como uma fase de potenciais riscos para o indivíduo e para a sociedade, uma real "zona de turbulência e contestação". GROSSMAN (2010, p. 48).

Mota e Rocha (2012) falam que nas últimas décadas, a transição da adolescência para a fase adulta tem vindo a ganhar relevância como objeto de estudo por parte da comunidade científica. Atualmente parece estar mais claro o papel da adolescência como antecedente de desenvolvimento à entrada na vida adulta, refletindo a transição para a independência e a consolidação da autonomia (p. 357).

\section{DEPRESSÃO E SUICIDÍO NA ADOLESCENCIA}

Lemos et al (2011 p.22) apud (Santos et al, 2007) a depressão é caracterizada como um transtorno de humor multifatorial que envolve aspectos afetivos, motivacionais, cognitivos e neurovegetativos que devem ser levados em conta em sua avaliação e tratamento.

A Organização Mundial de Saúde indica que nas próximas duas décadas haverá uma mudança nas necessidades de saúde da população mundial devido ao fato de que doenças como a depressão estão, rapidamente, substituindo os tradicionais problemas das doenças infecciosas e de má nutrição (BAHLS e BAHLS, 2002 p. 49).

Esteves e Galvan, dizem que a depressão é a alteração afetiva mais estudada e falada na atualidade. Classificada como um transtorno de humor, ela vem reger as atitudes dos sujeitos modificando a percepção de si mesmos, passando a enxergar suas problemáticas como grandes catástrofes. (2006, p.127).

Adolescentes com depressão apresentam-se principalmente irritáveis e instáveis, ao invés de demonstrarem ou queixarem-se de tristeza, podendo ocorrer crises freqüentes de explosão e raiva (BAHLS e BAHLS, p.5I).

Esteves e Galvan (2006) relatam que, a depressão é conhecida pelos sintomas descritos como apatia, irritabilidade, perda de interesse, tristeza, atraso motor ou agitação, idéias agressivas, desolação e múltiplas queixas somáticas (insônia, fadiga, anorexia). (p.127).

Baptista e Oliveira acrescentam que os principais sintomas da depressão estão relacionados com o humor deprimido, perda do interesse e prazer; energia reduzida, 
causando aumento da fatigabilidade e diminuição de atividades; concentração, atenção, auto-estima e autoconfiança reduzidas; idéias pessimistas do futuro; ideação suicida; alteração no sono e apetite diminuído, dentre outros (2004, p.54).

Baptista e Oliveira (2004) continuam esclarecendo que a depressão é um transtorno afetivo presente em todas as etapas do desenvolvimento; no entanto, somente há aproximadamente 40 anos é que este fenômeno vem sendo mais enfocado em crianças e adolescentes. O profissional da saúde e da educação deve estar atento aos sintomas de depressão em crianças e adolescente pois, assim, poderá detectar e diagnosticar diferencialmente tal transtorno, bem como propiciar tratamento adequado (p.54).

Os autores Benincasa e Rezende (2006) apud Dutra (200I), afirmam que a depressão se revela, comumente, através de sentimento de vazio, tédio, indiferença, solidão, abandono, impressão de ser mal-amado, incompreendido ou rejeitado. O autor acrescenta que os sinais da depressão podem ser "uma resposta inevitável" a um mundo sentido como frustrante (p. 95).

A depressão na adolescência gera enormes dificuldades tanto emocionais quanto sociais e intelectuais. $\mathrm{O}$ sofrimento causado pela depressão faz com que o jovem muitas vezes procure saídas rápidas, como o uso de substâncias psicoativas ou até mesmo o suicídio (ANDRADE E ARGIMON, 2008, p. 57I).

O suicídio no adolescente é o fato mais relevante do quadro clínico da depressão. Dentro do espectro do comportamento suicida situam-se as idéias suicidas, as tentativas de suicídio e o suicídio consumado (BAHLS, 2002, p. 53).

Organização Mundial da Saúde (OMS) conceitua o suicídio como um ato intencional do indivíduo para extinguir a própria vida. É um dano sério que vem aumentando em níveis preocupantes, fato que o torna uma importante questão para a saúde pública (SCHILICHTING, MORAES 2018, p. 358).

Segundo Braga e Dell'anglio (2013, p.3) o suicídio constitui-se, atualmente, em um problema de saúde pública mundial, pois está, em muitos países, entre as três principais causas de morte entre indivíduos de I5 a 44 anos e é a segunda principal causa de morte entre indivíduos de io a 24 anos.

Baptista e Oliveira (2004) falam que a crença e a sensação de que nada mais vai dar certo em sua vida podem levar esses adolescentes a intentar contra a própria vida, em busca de uma forma para sanar a dor (p.54).

Portanto, é preciso levar em consideração que:

Atualmente, as situações sociais, como empregabilidade e desemprego, estrutura familiar, condições socioeconômicas, padrão de possibilidades de consumo de insumos, como roupas, alimentos e lazer, aceitação no meio de convivência, entre outros fatores, interagem com as predisposições biológicas para o aparecimento do comportamento suicida (ABREU ET AL 2010, p. 196). 


\title{
FATORES DE RISCO, PREVENÇÃO DA DEPRESSÃO E DO SUICÍDIO
}

Bahls e Bahls (2002, p. I, 2) fatores de risco são a presença de conflito familiar, dúvida quanto à orientação sexual, presença de comorbidades, especialmente doenças crônicas, sexo feminino, imagem corporal ruim, história de abuso, baixa condição socioeconômica, identificação com grupos minoritários, falta de suporte familiar e poucas habilidades sociais.

\begin{abstract}
Benicasa e Rezende ressaltam que se deve estar atento para os seguintes sinais: os estados de humor irritável ou depressivo duradouro e/ou excessivo, os períodos prolongados de isolamento ou hostilidade com família e amigos; o afastamento da escola ou queda importante no rendimento escolar; o afastamento de atividades grupais e comportamentos como abuso de substâncias (álcool e drogas), violência física, atividade sexual imprudente e fugas de casa (2006, p.95).
\end{abstract}

Para Abreu et al, (2010) os problemas como dificuldades de relacionamento e de comunicação, ausência de afeto e falta de apoio familiar por vezes estão na origem de comportamentos suicidas. A disfuncionalidade familiar é um risco ainda maior para crianças e adolescentes, visto que as relações familiares são importantes no desenvolvimento do indivíduo (p.197).

Dutra (2002) considera que a solidão é um sentimento muito comum em adolescentes que tentam o suicídio. Tais jovens relatam sentir falta de ter amigos e reclamam não ter ninguém para dividir experiências e tristezas, apresentando maior probabilidade de desenvolver problemas emocionais, comportamentais e afetivos (Apud BRAGA e DELL'AGLIA, 2013, p.5).

De acordo com a Organização Mundial da Saúde (WHO, 20ıo), a vulnerabilidade associada à doença mental, à depressão, a desordens relacionadas ao álcool (alcoolismo), ao abuso, à violência, a perdas, à história de tentativa de suicídio, bem como à "bagagem" cultural e social representam os maiores fatores de risco ao suicídio (BRAGA e DELL'AGLIA, 2013, p.6)

Braga e Dell'Aglio (2013) apresentam outros fatores que têm sido apontados como riscos ao comportamento suicida, como a vulnerabilidade causada pela pobreza, o desemprego, a instabilidade familiar, pessoas com histórico de suicídio na família estão mais propicia a repetir o comportamento. Porém em adolescentes, as tentativas de suicídio e a perda recente de uma pessoa querida podem aumentar a probabilidade de suicídio.

Segundo Abreu et al (2010), apesar de o transtorno depressivo representar importante fator de risco para o problema, um estudo recente demonstrou que médicos que atuam na atenção primária à saúde questionam apenas metade dos usuários com depressão sobre o comportamento suicida (p.198).

Martins, Trindade e Almeida (2003), ao discutirem sobre fatores de proteção à depressão na adolescência, garantem que, ao mesmo tempo em que os adolescentes alegam precisar de 
liberdade para se divertir, instrui sobre a necessidade de apoio e de proteção para sentirem-se seguros. Os autores falam que, para o indivíduo, o bem-estar está ligado ao sentimento de proteção dados pelos pais. E acrescentam ainda que "o apoio e a proteção são elementos significativos para a vida e que a responsabilidade para seu futuro está, neste momento, colocada em agentes externos (pais, boa escola, entre outros)" (p. 567).

Baptista e Oliveira (2004) salienta a diferença entre estrutura e suporte familiar:

A estrutura familiar o número de pessoas de uma família e como se dispõe, ou seja, suas características físicas[...] já, o suporte familiar está relacionado aos aspectos psicológicos, como manifestação de carinho, atenção, diálogo, proximidade afetiva, liberdade, superproteção e independência existente entre os membros da família (p.54).

antana (2008) afirma que o contexto familiar é fundamental para o desenvolvimento do adolescente, pois possibilita um ambiente de proteção e tranquilidade contra as adversidades diárias, percebidas de forma mais intensa nessa etapa do desenvolvimento humano.

\section{CONCLUSÃO}

O artigo proporcionou a compreensão de alguns aspectos da depressão e do suicídio em adolescentes.

Sobre a depressão é importante ressaltar que é uma doença que ocasiona mudança de humor, falta de interesse, tristeza, irritabilidade, isolamento, piora no rendimento escolar, ocorre a automutilação, não sente prazer nas atividades do dia a dia, ou seja, perde o sentido da vida. Estes são alguns sinais para reconhecer que o adolescente está com depressão.

Em consequência da depressão pode ocorrer o suicídio que é um ato intencional do sujeito contra a própria vida. $\mathrm{O}$ adolescente pode apresentar comportamento suicida, como através da articulação, de seus atos e até mesmo cartas suicidas, tentativas de suicídio e o suicídio consumado.

Portanto, o propósito desse estudo foi contribuir, através da explanação de pesquisas referente a esse tema, para que a compreensão sobre essa doença e suas repercussões, seja ainda mais integral, assim sendo, é preciso ter uma atenção maior nessa fase da vida, e esquecer a famosa frase clichê que diz, " quem quer se matar não avisa", pois estão pedindo ajuda, e a sociedade ignora este fato.

\section{REFERÊNCIAS}

ABERASTURY, Arminda. KONABEL, Mauricio. Adolescente Normal um Enfoque Psicanalítico. Trad. de Suzana Maria Garagoray Ballve. Porto Alegre, arte médicas, I98I. 
ABREU et al. Comportamento suicida: fatores de risco e intervenções preventivas. Rev. Eletr. Enf. [Internet]. 2010;12(I):195-200. Available from: http://www.fen.ufg.br/revista/vi2/nI/vi2nia24.htm.

ANDRADE, Cláudia. Transição para a idade adulta: Das condições sociais às implicações psicológicas. Análise Psicológica (2010), 2 (XXVIII): 255-267.

ANDRADE, Tânia Moraes Ramos; ARGIMON, Irani Iracema de Lima. Sintomas Depressivos E Uso De Cannabis Em Adolescentes. Psicologia em Estudo, Maringá, v. I3, n. 3, p. $567-573$, jul./set. 2008

BAPTISTA. Makilim N; OLIVEIRA, Andreia A. Sintomatologia De Depressão E Suporte Familiar Em Adolescentes: Um Estudo De Correlação. Refere-se ao Art. de mesmo nome, I4(3), 58-67, 2004 Rev. Bras. Cresc. Des. Hum., S. Paulo, I4(3), I6-oo, 2004.

BAHLS, Saint-Clair ; BAHLS, Flávia Rocha Campos. Depressão na adolescência: características clínicas. Interação em Psicologia, 2002, 6(I), p. 49-57.

BENICASA, Miria; REZENDE, Manuel Morgado. Tristeza E Suicídio Entre Adolescentes: Fatores De Risco E Proteção. Boletim De Psicologia, 2006, Vol. Lvi, № 124: 93-ı10

BRAGA, Luiza de Lima; DELL'AGLIO, Débora Dalbosco. Suicídio na adolescência: fatores de risco, depressão e gênero. Contextos Clínicos, 6(I):2-14, janeiro-junho 2013.

EISENTEIN, Evelyn. Adolescência: definições, conceitos e critérios. volume $2, \mathrm{n}-2, \mathrm{j}$ junho 2005 Adolescência \& Saúde.

ESTEVES, Fernanda Cavalcante; GALVAN, Alda Luiza. Depressão numa contextualização contemporânea. Aletheia, n.24, p.127-135, jul./dez. 2006.

GROSSMAN, Eloisa. A Construção Do Conceito De Adolescência No Ocidente. Adolescência \& Saúde volume $7 \square$ no 3 प julho 2010.

LEMOS, Valdir Aquino; BAPTISTA, Makilim Nunes; CARNEIRO, Adriana Munhoz. Suporte Familiar, Crenças Irracionais e Sintomatologia Depressiva em Estudantes Universitários. PSICOLOGIA: CIÊNCIA E PROFISSÃ O, 20II, 3I (I), 20-29. 
open $\bigcirc$ access

MARTINS, Priscilla de Oliveira; TRINDADE, Zeidi Araújo; ALMEIDA, Ângela Maria de Oliveira. O Ter e o Ser: Representações Sociais da Adolescência entre Adolescentes de Inserção Urbana e Rural. Psicologia: Reflexão e Crítica, 2003, I6(3), pp. 555-568.

MOTA, Catarina Pinheiro, ROCHA, Magda. Adolescência e Jovem Adultícia: Crescimento Pessoal, Separação-Individuação e o Jogo das Relações. Psicologia: Teoria e Pesquisa Jul-Set 2012, Vol. 28 n. 3, pp. 357-366.

Prevenção Do Suicídio: Um Manual Para Profissionais Da Saúde Em Atenção Primária. Transtornos Mentais E Comportamentais Departamento De Saúde Mental Organização Mundial Da Saúde. Genebra 2000.

SANTANA, Priscilla Rodrigues. Suporte familiar, estilos parentais e sintomatologia depressiva: um estudo correlacional / Priscilla Rodrigues Santana. -- Itatiba, 2008.

SCHLICHTING, Carlos Alexandre; MORAES, Maria Cecília Leite. Mortalidade por suicídio na adolescência: uma revisão. ISSN 2318-8413 http://www.seer.uftm.edu.br/revistaeletronica/index.php/refacs REFACS (online) 2018; 6(Supl. I):357-363 < acesso em o6 de novembro de 2019>. 